\title{
Preparation and Adsorption Performance of Toluene on Montmorillonite Mesoporous Materials
}

\author{
CHEN Dingsheng ${ }^{1,2, a^{*}}$, ZENG Huanmu ${ }^{1,2}$, CEN Chaoping ${ }^{1,2, b^{*}}$, CHEN \\ Zhihang $^{1,2}$, FANG Ping ${ }^{1,2}$, ZHANG Yukui ${ }^{1,2}$, CHEN Xiongbo ${ }^{1,2}$, and TANG \\ Zijun ${ }^{1,2}$ \\ ${ }^{1}$ South China Institute of Environmental Sciences, the Ministry of Environmental Protection of PRC, \\ Guangzhou 510655, China \\ ${ }^{2}$ Key Laboratory of Water and Air Pollution Control of Guangdong Province, Guangzhou 510655, \\ China \\ a chendingsheng@scies.org, ${ }^{\mathrm{b}}$ cenchaoping@scies.org
}

Keywords: Montmorillonite, Mesoporous materials, Volatile organic compounds

Abstract. Volatile Organic Compounds (VOCs) is one of the important atmospheric pollutants. It is important to develop materials and technologies for VOCs treatment. Adsorption is recognized as a relatively excellent VOCs control technology. Montmorillonite is selected as a base material for the preparation of VOCs adsorbents. Templating agent, acid activation, pillar support and other means were systematic research to synthetic PCHs, and adjusting its physical and chemical properties such as specific surface area, pore size and pore volume, the adsorption material with better adsorption performance was obtained. It is a good prospect in the application of VOCs adsorption.

\section{Introduction}

China's environmental pollution incidents have occurred repeatedly because of the rapid economic development and the gradual activation of industrial production. These environmental problems have seriously threatened the lives and property of the people. Among them, Volatile Organic Compounds (VOCs) are one of the most important sources of pollution in the atmospheric environment ${ }^{[1-2]}$.

Montmorillonite has the characteristics of abundant reserves, low price, good thermal stability and environmental friendliness ${ }^{[3-4]}$. In this paper, calcium montmorillonite and sodium montmorillonite are used as raw material, and the organic pillar is firstly used to obtain organic montmorillonite and Hydrolysis polymerization of under the action of calcium montmorillonite and sodium montmorillonite are respectively, added by adding a certain proportion of ethyl orthosilicate and neutral amine co-template agent. The porous montmorillonite isomers ( $\mathrm{Na} / \mathrm{Ca}$-PCHs) at various temperatures were prepared by different temperature calcinations.

The application of natural montmorillonite to develop stable and efficient environmental protection materials is a great benefit for social and environmental. It is of great practical significance to solve the problem of environmental pollution in China and respond quickly to environmental pollution emergencies. This subject is intended to prepare an environmentally friendly adsorbent with stable, efficient, and recyclable regeneration that does not cause secondary pollution to the environment.

\section{Experimental materials and methods}

Experimental Materials Toluene, Tetraethyl silicate, Sodium hydroxide, Dodecylamine, Cetyltrimethylammonium Bromide (CTAB), analytical reagent, Tianjin Institute of Fine Chemical rehabilitation; Sulfuric acid , chemically pure reagent, Tianjin Branch-Europe Chemical Reagent Co, Ltd; Experimental water for the distilled water.

Experimental methods and procedures The calcium montmorillonite (Ca-Mt) is treated with sodium to obtain an sodium montmorillonite (Na-Mt).

Preparation method of porous montmorillonite isomerous material: calcium-based montmorillonite 
(Ca-Mt) or sodium montmorillonite (Na-Mt), dodecylamine and silicon obtained above Ethyl acetate (TEOS) were mixed in a ratio of 1:20:150. The specific procedure is: appropriate amount of dodecylamine, pour in beakers, $100 \mathrm{ml}$ ultrapure water, and mix them with an electric stirrer under normal temperature conditions; then add a certain amount and the same amount. Ca-Mt and Na-Mt were respectively added to the beakers and stirring for 2 hours; an appropriate amount of ethyl orthosilicate were added and the reaction was stirred for 6 hours; the gel-like solid was separated by a centrifuge, and then dried to a solid at $105^{\circ} \mathrm{C}$. The two materials were respectively in a programmed muffle furnace at 500,600 and $700^{\circ} \mathrm{C}$ for $4 \mathrm{~h}$. By remove organic and organic surfactants, three different temperatures of $\mathrm{Ca}-\mathrm{PCH}$ and $\mathrm{Na}-\mathrm{PCH}$ were obtained.

\section{Experimental conclusions and discussion}

\section{specific surface area and pore size analysis}

It is important to measure and analyze the pore structure of the adsorbent, the adsorbent specific surface area is a very important parameter to influences its adsorption performance. The greater the specific surface area can provide greater chemical reaction contact space, both for catalytic or adsorptive enhancement.

According to the Table 1, the determination of the structural parameters of each sample results are: (1) calcium-based and sodium montmorillonite porous heterogeneous materials without firing, the specific surface areas were $419.6 \mathrm{~m}^{2} / \mathrm{g}$ and $349.3 \mathrm{~m}^{2} / \mathrm{g}$ respectively. after high temperature calcination $4 \mathrm{~h}$, the specific surface area increased significantly ${ }^{[5]}$. (2) The specific surface area of Ca-PCHs increased by 56\%, 60\% and 58\% respectively after calcined at 500, 600 and $700{ }^{\circ} \mathrm{C}$ for $4 \mathrm{~h}$. After Na-PCHs calcined at 500, 600 and $700{ }^{\circ} \mathrm{C}$ for $4 \mathrm{~h}$, the specific surface area of Na-PCHs increased by $101 \%, 104 \%$ and $103 \%$ respectively, twice compared to the original. The larger the specific surface area is, the more room for chemical reaction can be provided. (3) Although the specific surface area of the porous material of sodium montmorillonite after calcination increases, However, the calcination temperature of $500 \sim 700{ }^{\circ} \mathrm{C}$, the difference between the two materials is not significant. (4) Calcium-based and sodium montmorillonite are the best performance calcined at $600{ }^{\circ} \mathrm{C}$, the specific surface area is $673.1 \mathrm{~m}^{2} / \mathrm{g}$ and $713.7 \mathrm{~m}^{2} / \mathrm{g}$ respectively, compared to the original increased by $60 \%$ and $104 \%$.

Table 1 Structural parameters of each sample

\begin{tabular}{ccccc}
\hline Sample & $\begin{array}{c}\text { Specific Surface } \\
\text { Area }\left(\mathrm{m}^{2} / \mathrm{g}\right)\end{array}$ & $\begin{array}{c}\text { Pore Volume } \\
\left(\mathrm{cm}^{3} / \mathrm{g}\right)\end{array}$ & $\begin{array}{c}\text { Average Pore } \\
\text { Volume }\left(\mathrm{cm}^{3} / \mathrm{g}\right)\end{array}$ & $\begin{array}{c}\text { Average Pore } \\
\text { Size }(\mathrm{nm})\end{array}$ \\
\hline $\mathrm{Mt}$ & 37.2 & 0.13 & 0.15 & 15.86 \\
$\mathrm{Ca}-\mathrm{PCHs}$ & 419.6 & 0.38 & 0.44 & 3.19 \\
$\mathrm{Ca}-\mathrm{PCHs} 500^{\circ} \mathrm{C}$ & 658.7 & 0.62 & 0.69 & 3.24 \\
$\mathrm{Ca}-\mathrm{PCHs} 600^{\circ} \mathrm{C}$ & 673.1 & 0.64 & 0.71 & 3.24 \\
$\mathrm{Ca}-\mathrm{PCHs} 700^{\circ} \mathrm{C}$ & 664.4 & 0.59 & 0.66 & 3.15 \\
$\mathrm{Na}-\mathrm{PCHs}$ & 349.3 & 0.35 & 0.42 & 3.93 \\
$\mathrm{Na}-\mathrm{PCHs} 500^{\circ} \mathrm{C}$ & 705.0 & 0.66 & 0.76 & 3.57 \\
$\mathrm{Na}-\mathrm{PCHs} 600^{\circ} \mathrm{C}$ & 713.7 & 0.67 & 0.77 & 3.61 \\
$\mathrm{Na}-\mathrm{PCHs} 700^{\circ} \mathrm{C}$ & 709.7 & 0.65 & 0.75 & 3.55 \\
\hline
\end{tabular}

Mesoporous molecular sieve refers to the pore size of $2 \sim 50 \mathrm{~nm}$ molecular sieve collectively. Hole capacity: $\mathrm{Ca} / \mathrm{Na}-\mathrm{PCH} 600{ }^{\circ} \mathrm{C}>\mathrm{Ca} / \mathrm{Na}-\mathrm{PCH} 500{ }^{\circ} \mathrm{C}>\mathrm{Ca} / \mathrm{Na}-\mathrm{PCH}$ (original), because calcined to remove the sample template, make sample pore volume increase; calcination $700{ }^{\circ} \mathrm{C}$ pore 
volume decreases, the reason is the temperature is too high, part of the hole structure collapse caused by pore size becomes smaller. Different temperature stages, the pore volume of calcium-based materials are larger than the pore volume of sodium-based materials, more adsorption sites. At $600{ }^{\circ} \mathrm{C}$ high temperature roasting, the pore volume of both samples increased, adsorption enhanced. Figure 1 shows the pore size distribution of $\mathrm{BJH}$ after calcination at $600{ }^{\circ} \mathrm{C}$ for 4 hours with representative Ca-mononitrate porous heterogeneous materials (Ca-PCHs) and Na-montmorillonite porous heterogeneous materials (Na-PCHs).

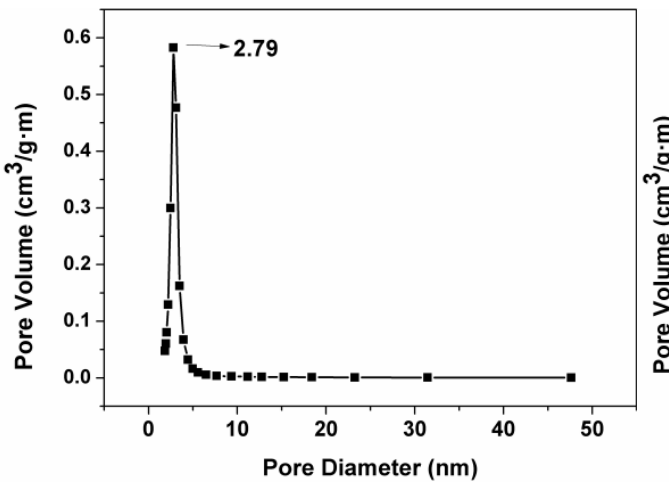

$\mathrm{Ca}-\mathrm{PCHs} 600^{\circ} \mathrm{C}$

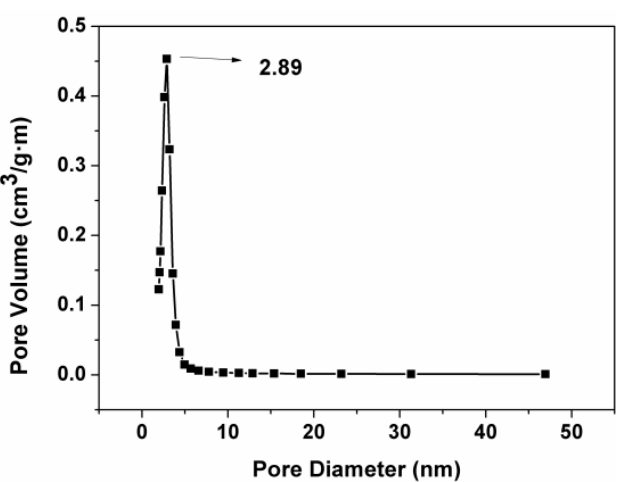

$\mathrm{Na}-\mathrm{PCH} 600^{\circ} \mathrm{C}$

Figure 1 BJH pore size distribution of each sample

\section{Porous montmorillonite isomerous materials on the static adsorption properties of VOCs}

Determination of static adsorption properties

In this paper, the adsorption capacity of toluene is used as the adsorption capacity of VOCs. After $24 \mathrm{~h}$ adsorption of toluene on the material was measured, the determination of saturated adsorption of toluene for two kinds of adsorbents prepared from two different raw materials (Na-PCHs $600{ }^{\circ} \mathrm{C}$, Ca-PCHs $600{ }^{\circ} \mathrm{C}$ ) with the best $24 \mathrm{~h}$ adsorption capacity and specific surface area were selected.

static adsorption performance results and discussion

Static adsorption experiment is to determine the material saturated adsorption capacity of gaseous pollutants commonly used methods. The saturated adsorption capacity is determined by the weight difference before and after measuring the parallel experimental adsorbent. According to the measurement results in Table 1 and Figure 2, (1) two samples in the second time (ie adsorption 24h), The amount of toluene adsorbed almost reached its peak. (2) a curve can be clearly seen: the saturated adsorption capacity of toluene: Na-PCHs $600{ }^{\circ} \mathrm{C}>\mathrm{Ca}-\mathrm{PCHs} 600{ }^{\circ} \mathrm{C}$, description Na-PCHs calcined at $600{ }^{\circ} \mathrm{C}$ for $4 \mathrm{~h}$ conditions, with the maximum saturated adsorption of toluene. 


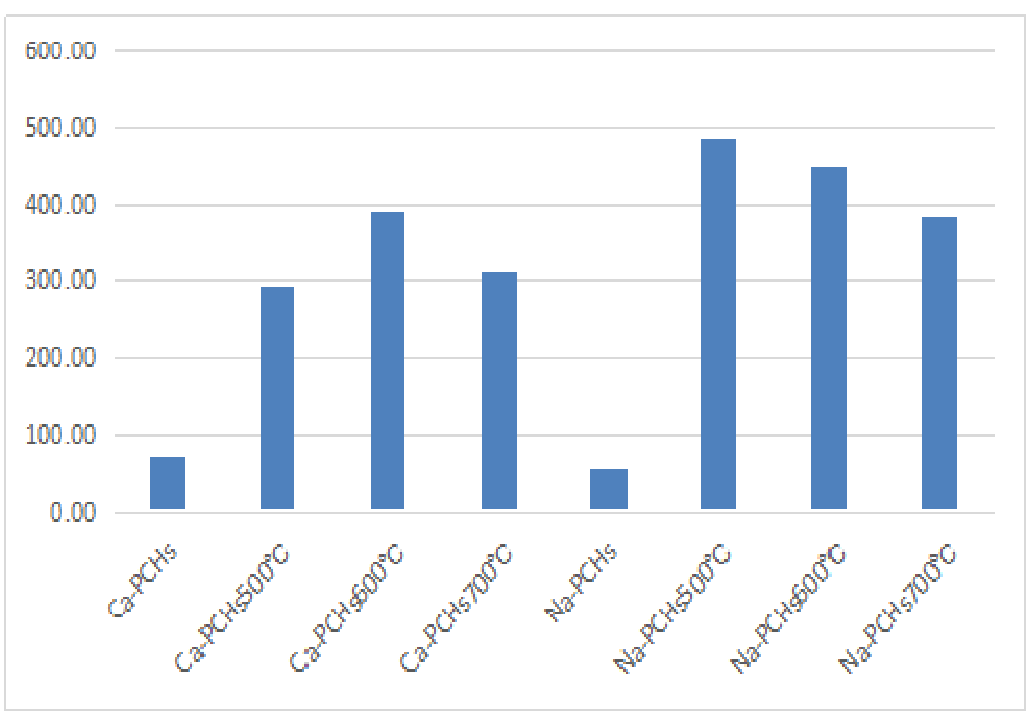

Figure 2 Adsorption capacity of toluene for $24 \mathrm{~h}(\mathrm{mg} / \mathrm{g})$

\section{Conclusions}

In general, the calcium-based montmorillonite adsorption capacity of toluene than sodium montmorillonite, three temperature of the Ca-PCHs desorption efficiency can reach $86 \%$ to $95 \%$, $\mathrm{Na}-\mathrm{PCH}$ desorption efficiency of only $76 \%$ to $87 \%$. As shown in Figure 3, the average amount of sodium montmorillonite isomerized materials adsorbed toluene higher than the calcium-based by amount of adsorption $10 \%$.

\section{Acknowledgements}

The research was supported by Nature Science Foundations of China (51408256, 51778264), the Science and Technology Key Projects of Guangdong Province (2017A030223005, 2016B020241002, 2016A020221017), the Science and Technology Program of Guangzhou City (201804010147), Special Funds for Research from the Environmental Charity Project of South China Institute of Environmental Sciences.

\section{References}

[1] Zhang Zhijuan, Yan Xiuying,Gao Feilong, et al. Emission and health risk assessment of volatile organic compounds in various processes of a petroleum refinery in the Pearl River Delta, China[J] .Environmental pollution, 2018, 238: 452-461.

[2] Song Congbo, Wu Lin, Xie Yaochen, et al. Air pollution in China: Status and spatiotemporal variations [J]. Environmental Pollution, 2017, 227: 334-347.

[3] Deng Liangliang, Yuan Peng, Liu Dong, et al. Effects of microstructure of clay minerals, montmorillonite, kaolinite and halloysite, on their benzene adsorption behaviors [J]. Applied Clay Science, 2017, 143: 184-191.

[4] Ding Menglin, Zuo Shufeng, Qi Chenze. Preparation and characterization of novel composite AlCr-pillared clays and preliminary investigation for benzene adsorption [J]. Applied Clay Science, 2015, 115:9-16.

[5] Aguiar, J. E., Cecilia, J. A., Tavares, P. A. S., et al. Adsorption study of reactive dyes onto porous clay heterostructures [J]. Applied Clay Science, 2017, 135: 35-44. 